\title{
Therapeutic efficacy of amoxicillin and rifaximin in patients with small intestinal bacterial overgrowth and Helicobacter pylori infection
}

\author{
Paulina Konrad ${ }^{1}$, Jan Chojnacki ${ }^{1}$, Anita Gąsiorowska ${ }^{2}$, Cezary Rudnicki ${ }^{2}$, Aleksandra Kaczka ${ }^{1}$, Cezary Chojnacki $^{1}$ \\ ${ }^{1}$ Department of Clinical Nutrition and Gastroenterological Diagnostics, Medical University of Lodz, Lodz, Poland \\ ${ }^{2}$ Department of Gastroenterology, Medical University of Lodz, Lodz, Poland
}

Gastroenterology Rev 2018; 13 (3): 213-217

DOI: https://doi.org/10.5114/pg.2018.74228

Key words: small intestinal bacterial overgrowth, Helicobacter pylori, therapy, rifaximin, amoxicillin.

Address for correspondence: Paulina Konrad, Department of Clinical Nutrition and Gastroenterological Diagnostics, Medical University of Lodz, 1 Plac Hallera, 90-647 Lodz, Poland, phone: +48 508944 911, e-mail: paulina.konrad@umed.lodz.pl

\begin{abstract}
Introduction: Small intestinal bacterial overgrowth (SIBO) may coexist with Helicobacter pylori infection, which can be the cause of chronic gastrointestinal complaints.

Aim: Evaluation of the therapeutic efficacy of amoxicillin and rifaximin in the treatment of these diseases.

Material and methods: The lactulose hydrogen breath test (LHBT) and the urea breath test $\left({ }^{13} \mathrm{C}-\mathrm{UBT}\right)$ were performed in 116 patients. In 62 patients the coexistence of small intestinal bacterial overgrowth and $H$. pylori infection was observed. Then, in group I $(n=30)$ pantoprazole $(2 \times 40 \mathrm{mg})$, amoxicillin $(2 \times 1000 \mathrm{mg})$ and metronidazole $(2 \times 500 \mathrm{mg})$ and in group II $(n=32)$ pantoprazole and amoxicillin at the above doses and rifaximin $(3 \times 400 \mathrm{mg})$ were administered for 10 days. After 6 weeks, both breath tests were repeated and the degree of remission of symptoms was measured using a 10-point visual analog scale (VAS).

Results: After the treatment the LHBT index decreased in group I from $61.2 \pm 19.4 \mathrm{ppm}$ to $22.0 \pm 8.2 \mathrm{ppm}(p<0.001)$ and in group II from $59.6 \pm 15.5 \mathrm{ppm}$ to $15.2 \pm 8.6 \mathrm{ppm}(p<0.001)$. Eradication of $H$. pylori $\left({ }^{13} \mathrm{C}\right.$-UBT below $4.0 \%$ ) was achieved in $63.3 \%$ of patients in group I and $59.4 \%$ in group II $(p>0.05)$. The decrease of pain below 3.0 points in the VAS was obtained in $64.8 \%$ of patients in group I and in $56.2 \%$ in group II.

Conclusions: Combination of amoxicillin and rifaximin may be effective in the treatment of patients with small intestinal bacterial overgrowth syndrome and concomitant $H$. pylori infection.
\end{abstract}

\section{Introduction}

Small intestinal bacterial overgrowth (SIBO) is a common gastrointestinal dysbiosis. Overuse of medicines, including proton pump inhibitors [1], can be one of the causes. Long-term reduction of gastric secretion creates favorable conditions for the colonization of various bacterial species in the upper gastrointestinal tract [2-4]. In some people these infections are asymptomatic but they are not devoid of adverse effects.

Helicobacter pylori infection always results in the development of chronic gastritis and can lead to cancers of this organ. Furthermore, this infection disturbs the secretion of many tissue hormones such as gastrin, ghrelin, obestatin [5-7] and leads to metabolic disorders, insulin resistance and obesity [8-10]. It is believed that excess of bacteria in the small intestine evokes similar changes in lipid and carbohydrate metabolism [11, 12]. According to the Kyoto consensus, H. pylori eradication should also apply to the population with asymptomatic infection [13]. Likewise, maintaining eubiosis in the small intestine is a condition for maintaining a good psychosomatic state [14]. In practice, antimicrobial therapy is usually applied in the case of the occurrence of clinical symptoms. Helicobacter pylori infection is mainly manifested by epigastric pain and the small intestinal bacterial overgrowth causes abdominal pain and bloating as well as abnormalities in bowel movements [15]. The above changes in gastric and intestinal microflora often coexist, which makes the diagnostic and therapeutic management difficult [1618]. It is not always possible to determine the cause of ailments, the order of antibiotic treatment and which antibiotics will be effective. Amoxicillin, clarithromycin, 
levofloxacin, tetracycline and metronidazole are most frequently used in the treatment of $H$. pylori infection [19]. Rifaximin appeared to be the most effective in the treatment of SIBO [20, 21]. Rifaximin was previously demonstrated to be active against $H$. pylori [22].

\section{Aim}

The aim of the study was to evaluate the antibacterial efficacy of amoxicillin in combination with rifaximin in patients with small intestinal bacterial overgrowth syndrome and $H$. pylori infection.

\section{Material and methods}

The study included 116 patients aged 27-64 years (mean age: $44.1 \pm 12.3$ ) in the years 2012-2017. The patients were examined and treated at the Department of Clinical Nutrition and Gastroenterological Diagnostics and at the Department of Gastroenterology of the Medical University of Lodz.

\section{Inclusion criteria}

Due to abdominal pain, bloating, diarrhea or constipation all patients initially underwent the lactulose hydrogen breath test (LHBT), using a breath hydrogen analyzer (Gastrolyzer, Bedfont Scientific Ltd, UK). The test result was considered positive (confirming SIBO) when an increase in the concentration of hydrogen in the expired air was above 20 ppm (percent per million) within $60 \mathrm{~min}$ of ingesting $25 \mathrm{ml}$ of lactulose in accordance with generally accepted criteria [23]. Then, in LHBT-positive patients a breath test was performed using $75 \mathrm{mg}$ of ${ }^{13} \mathrm{C}$-labeled urea and a FAN-ci 2 device set (Fisher ANalysen Instrumente $\mathrm{GmbH}$ ). The test result was considered positive for $\mathrm{H}$. pylori infection when the concentration of carbon dioxide in the exhaled air was above $4.0 \%$ at $30 \mathrm{~min}$.

Table I. General characteristics of patients included in study; differences no significant

\begin{tabular}{lcc} 
Features & Group I $(n=30)$ & Group II $(n=28)$ \\
\hline Age [years] & $42.6 \pm 8.2$ & $45.4 \pm 11.0$ \\
\hline $\begin{array}{l}\text { Gender: } \\
\text { Male }\end{array}$ & $12(40 \%)$ & $10(35.7 \%)$ \\
\hline Female & $18(60 \%)$ & $18(64.3 \%)$ \\
\hline BMI [kg/m²] & $25.9 \pm 3.1$ & $26.5 \pm 2.9$ \\
\hline LHBT [ppm] & $61.2 \pm 19.4$ & $9.5 \pm 15.5$ \\
\hline UBT (\%o) & $18.5 \pm 3.8$ & $15.7 \pm 8.4$
\end{tabular}

$B M I$ - body mass index, LHBT - lactulose hydrogen breath test, UBT - urea breath test.

\section{Exclusion criteria}

Exclusion criteria: gastric and duodenal ulcer, Crohn's disease, ulcerative and lymphocytic colitis, celiac disease, mental and metabolic disorders, previous treatment for $\mathrm{H}$. pylori infection.

Differential diagnostic procedures concerned all patients and included endoscopy and ultrasonography of abdominal organs and routine laboratory tests: complete blood count, bilirubin, aspartate aminotransferase (AST), alanine aminotransferase (ALT), $\gamma$-glutamyltransferase (GGTP), alkaline phosphatase (ALP), amylase, lipase, urea, creatinine, glucose, cholesterol, triglycerides, thyroid-stimulating hormone (TSH).

\section{Therapeutic procedures}

In 62 of 116 subjects SIBO was found to coexist with $H$. pylori infection and these patients were randomly included in further studies and divided into two groups with single blind administration of medication. Group I $(n=30)$ patients were assigned to take pantoprazole $(2 \times 40 \mathrm{mg})$, amoxicillin $(2 \times 1000 \mathrm{mg})$ and metronidazole $(2 \times 500 \mathrm{mg})$ for 10 days and group II patients $(n=32)$ were assigned to take pantoprazole and amoxicillin at the same dose and rifaximin the dose of $3 \times 400 \mathrm{mg}$ also for 10 days. Furthermore, during the treatment and 6 weeks afterwards the patients were advised to follow the same balanced diet. Six weeks after the therapy both tests (LHBT and ${ }^{13} \mathrm{C}-\mathrm{UBT}$ ) were repeated and pain intensity was assessed using a 10-point visual analog scale (VAS).

\section{Ethics}

The patients' written consent and the approval of the Bioethics Committee of the Medical University of Lodz were obtained (RNN/11/17KE). The study was conducted in accordance with the Declaration of Helsinki and the principles of Good Clinical Practice (GCP).

\section{Statistical analysis}

In the statistical analysis Student's $t$ test was used for normal distribution and the Mann-Whitney test and $\chi^{2}$ test were used to compare the results of two different groups. The correlation between the above parameters was estimated with the Spearman correlation and linear regression equation. The calculations were performed with Statistica 9.1 software.

\section{Results}

In the preliminary statistical analysis of the two examined groups there were no significant differences in relation to age, gender, nutritional status or indices of small intestinal bacterial overgrowth and H. pylori colonization intensity in the stomach (Table I). 
Table II. Correlation between intensity of symptoms (points) and results of lactulose hydrogen breath test (LHBT) and urea breath test (UBT)

\begin{tabular}{lcc} 
Parameter & \multicolumn{2}{c}{ Symptoms (points) } \\
\cline { 2 - 3 } & Group I & Group II \\
\hline LHBT [ppm] & $r=0.850$ & $r=0.456$ \\
& $p<0.001$ & $p<0.05$ \\
\hline UBT (\%) & $r=0.242$ & $r=0.339$ \\
& $p>0.05$ & $p>0.05$
\end{tabular}

A positive correlation was found between small intestinal bacterial overgrowth index and pain intensity in both groups: group I, $r=0.850, p<0.001$, and group II, $r=0.456, p<0.05$ (Table II).

Also a positive, but weaker correlation was found between the level of $H$. pylori colonization and the intensity of gastrointestinal symptoms: in group I, $r=$ $0.242, p>0.05$, and in group $\mathrm{II}, r=0.339, p>0.05$ (Table II).

After the treatment, the SIBO index decreased from $61.2 \pm 19.4 \mathrm{ppm}$ to $22.0 \pm 8.2 \mathrm{ppm}(p<0.001)$ in group I and in group II from $59.5 \pm 15.7 \mathrm{ppm}$ to $15.7 \pm 8.4 \mathrm{ppm}$ $(p<0.001)$. A normal result, i.e. less than 20 ppm, was obtained in 18 (60.0\%) group I patients and in 21 (75\%) in group II; the difference between groups was statistically insignificant (Figure 1).

The index of $\mathrm{H}$. pylori colonization in the stomach also decreased, in group I from $18.4 \pm 3.8 \%$ o to 5.9 $\pm 5.4 \%$ o $(p<0.001)$ and in group II from $21.4 \pm 3.8 \%$ o to $6.5 \pm 4.6 \%$ o $(p<0.001)$. A result below $4.0 \%$ o was obtained in 19 (63.3\%) patients in group I and 19 (59.4\%) in group II; the difference between the groups was statistically insignificant (Figure 2).

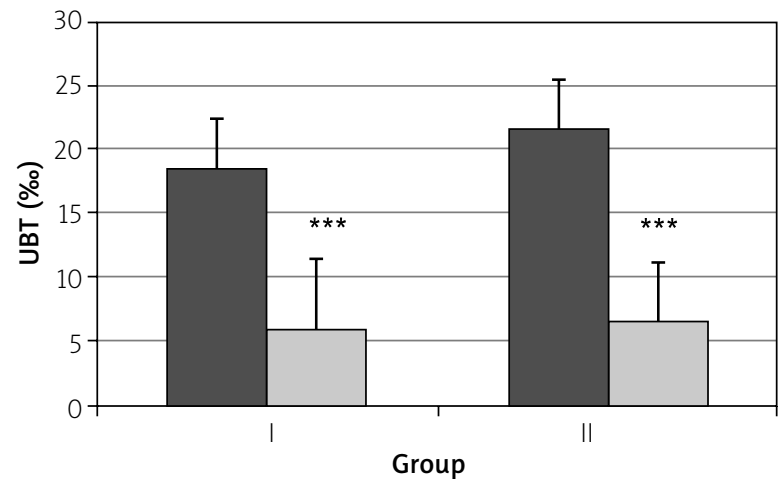

Figure 2. Results of urea breath test (UBT) before and after treatment with amoxicillin and metronidazole (group I) or with amoxicillin and rifaximin (group II) in patients with small intestinal bacterial overgrowth (SIBO) and $H$. pylori infection; ${ }^{* * *} p<0.001$

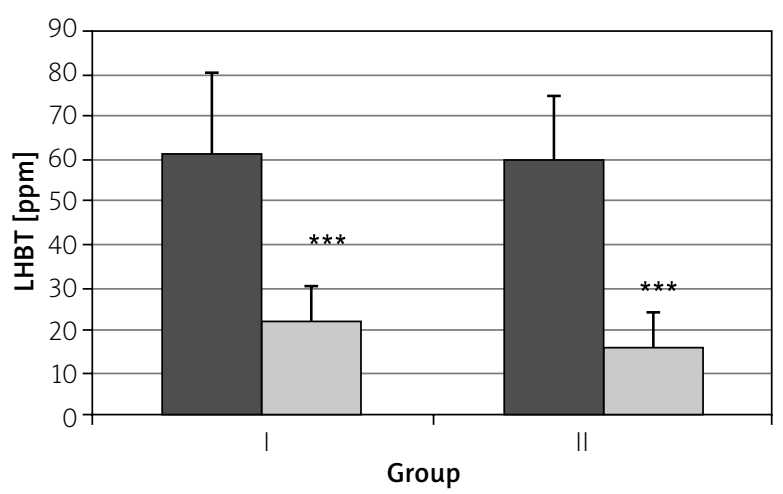

Figure 1. Results of lactulose hydrogen breath test (LHBT) before and after treatment with amoxicillin and metronidazole (group I) or with amoxicillin and rifaximin (group II) in patients with small intestinal bacterial overgrowth (SIBO) and H. pylori infection $\left({ }^{* * *} p<0.0001\right)$

Pain intensity decreased after treatment in group I from $7.1 \pm 1.5$ points to $4.6 \pm 1.6$ points $(p<0.01)$ and in group II from $7.2 \pm 1.1$ to $2.9 \pm 1.2$ points $(p<0.001)$ (Figure 3).

A reduction of pain below 3.0 points was obtained in $53.5 \%$ of group I patients and in $56.2 \%$ in group II $(p>0.05)$.

Drug tolerance was good in both groups. Only 3 patients from group I complained of mild nausea allowing for the treatment completion.

\section{Discussion}

The results of our study confirm the possibility of small intestinal bacterial overgrowth and $H$. pylori infection coexistence. Thus there is a need for diagnostic

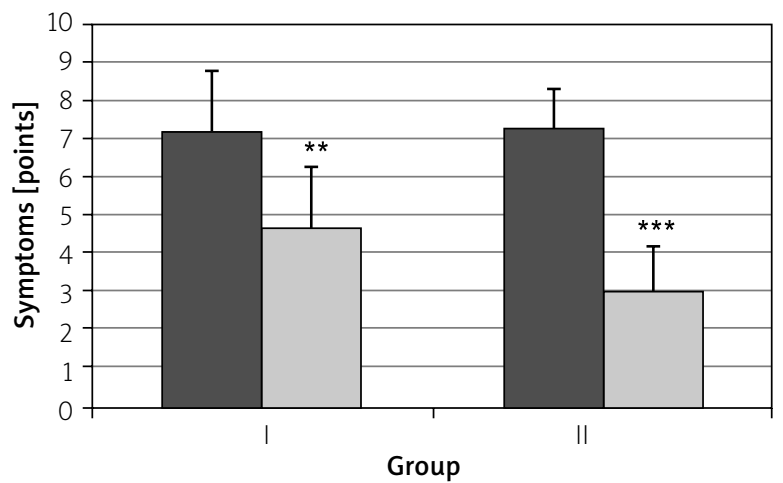

Figure 3. Intensity of gastrointestinal symptoms before and after treatment with amoxicillin and metronidazole (group I) or with amoxicillin and rifaximin (group II) in patients with small intestinal bacterial overgrowth and $H$. pylori infection 
tests in patients with a variety of upper gastrointestinal symptoms. The rational choice of treatment is also facilitated.

Our study showed that the combination of amoxicillin with rifaximin may be effective already in the firstline treatment of $H$. pylori infection. The eradication rate was not satisfactory $(64.0 \%)$, which may require prolongation of the therapy up to 14 days. Nevertheless, such combination treatment is justified in the case of H. pylori infection and small intestinal bacterial overgrowth. Good clinical outcomes and regression of gastrointestinal symptoms are in favor of this.

Amoxicillin and metronidazole were most frequently used for the eradication of $\mathrm{H}$. pylori in the first stage of treatment. Due to the increasing resistance of this bacterium to metronidazole, this drug is being replaced by other antibiotics such as clarithromycin, tetracycline and levofloxacin, but their efficacy is also unsatisfactory. These antibiotics have also been used in the treatment of other bacterial gastrointestinal infections as well as small intestinal bacterial overgrowth [24]. Di Stefano et al. [25] pointed to even greater efficacy of metronidazole in the treatment of SIBO compared to rifaximin. However, the results of numerous recent studies indicate that rifaximin is the most effective and safest in the treatment of small intestinal bacterial overgrowth syndrome [26]. The manufacturer of rifaximin lists its activity also against $H$. pylori. This information is based on the results of previous research. Mégraud et al. [22] observed this property in in vitro studies. Holton et al. [27] confirmed such an anti-bacterial effect of rifaximin in combination with ampicillin and metronidazole. De Giorgio et al. [28] demonstrated the efficacy of rifaximin $(3 \times 600 \mathrm{mg})$ in combination with amoxicillin $(2 \times 1000 \mathrm{mg})$ in the eradication of H. pylori. Quesada et al. [29] demonstrated the efficacy of rifaximin against clarithromycin-resistant $H$. pylori strains. According to Gasbarrini et al. [30] the eradication efficacy of rifaximin is high enough when administered at $1200 \mathrm{mg}$ for 10-14 days. Nizhevich et al. [31] obtained good results of $H$. pylori eradication using rifaximin with furazolidone and bismuth for 10 days. Yun et al. [32] demonstrated the efficacy of 7-day rifaximin $(3 \times 200 \mathrm{mg})$ and levofloxacin $(2 \times 500 \mathrm{mg})$ therapy in patients with $H$. pylori resistance to previous triple or quadruple therapy. Choi et al. [33] believe that rifaximin should be used more often in the second-and third-line combined eradication therapy.

Other advantages of this treatment are good tolerance of drugs and the possibility of repeated therapy in the case of a relapse. However, these suggestions require further investigations and more patients in the groups [34].

\section{Conclusions}

Combination of amoxicillin with rifaximin may be a useful method of treating patients with small intestinal bacterial overgrowth and concomitant $H$. pylori infection.

\section{Conflict of interest}

The authors declare no conflict of interest.

\section{References}

1. Lombardo L, Foti M, Ruggia O, Chiecchio A. Increased incidence of small intestinal bacterial overgrowth during proton pump inhibitor therapy. Clin Gastroenterol Hepatol 2010; 8: 504-8.

2. Marlicz W, Loniewski I, Grimes DS, Quigley EM. Nonsteroidal anti-inflammatory drugs, proton pump inhibitors, and gastrointestinal injury: contrasting interactions in the stomach and small intestine. Mayo Clin Proc 2014; 89: 1699-709.

3. Fujimori $\mathrm{S}$. What are the effects of proton pump inhibitors on the small intestine? World J Gastroenterol 2015; 21: 6817-9.

4. Compare D, Pica L, Rocco A, et al. Effects of long-term PPI treatment on producing bowel symptoms and SIBO. Eur J Clin Invest 2011; 41: 380-6.

5. Osawa $\mathrm{H}$, Kita $\mathrm{H}$, Ohnishi $\mathrm{H}$, et al. Changes in plasma ghrelin levels, gastric ghrelin production, and body weight after Helicobacter pylori cure. J Gastroenterol 2006; 41: 954-61.

6. Jang EJ, Park SW, Park JS, et al. The influence of the eradication of Helicobacter pylori on gastric ghrelin, appetite, and body mass index in patients with peptic ulcer disease. J Gastroenterol Hepatol 2008; 23 Suppl 2: 278-85.

7. Ulasoglu C, Isbilen B, Doganay L, et al. Effect of Helicobacter pylori eradication on serum ghrelin and obestatin levels. World J Gastroenterol 2013; 19: 2388-94.

8. Gen R, Demir M, Ataseven H. Effect of Helicobacter pylori eradication on insulin resistance, serum lipids and low-grade inflammation. South Med J 2010; 103: 190-6.

9. Albaker WL. Helicobacter pylori infection and its relationship to metabolic syndrome: is it a myth or fact? Saudi J Gastroenterol 2011; 17: 165-9.

10. Ferolla SM, Armiliato GN, Couto CA, Ferrari TC. The role of intestinal bacteria overgrowth in obesity-related nonalcoholic fatty liver disease. Nutrients 2014; 6: 5583-99.

11. Schwiertz A, Taras D, Schäfer K, et al. Microbiota and SCFA in lean and overweight healthy subjects. Obesity 2010; 18: 190-5.

12. Stachowicz N, Kiersztan A. The role of gut microbiota in the pathogenesis of obesity and diabetes. Postepy Hig Med Dosw 2013; 67: 288-303.

13. Sugano K, Tack J, Kuipers EJ, et al. Faculty members of Kyoto Global Consensus Conference. Kyoto global consensus report on Helicobacter pylori gastritis. Gut 2015; 64: 1353-67.

14. Bayeli PF, Mariottini M, Lisi L, et al. Guidelines on intestinal dysmicrobism (SIBO Small Intestine Bacterial Overgrowth). Minerva Gastroenterol Dietol 1999; 45: 297-308.

15. Gasbarrini A, Lauritano EC, Gabrielli M, et al. Small intestinal bacterial overgrowth: diagnosis and treatment. Dig Dis 2007; 25: 237-40. 
16. Enko D, Kriegshäuser G. Functional 13C-urea and glucose hydrogen/methane breath tests reveal significant association of small intestinal bacterial overgrowth in individuals with active Helicobacter pylori infection. Clin Biochem 2017; 50: 46-9.

17. Schulz C, Koch N, Schütte K, et al. H. pylori and its modulation of gastrointestinal microbiota. J Dig Dis 2015; 16: 109-17.

18. Llorca L, Pérez-Pérez G, Urruzuno P, et al. Characterization of the gastric microbiota in a pediatric population according to Helicobacter pylori status. Pediatr Infect Dis J 2017; 36: 173-8.

19. Sheh A, Fox JG. The role of the gastrointestinal microbiome in Helicobacter pylori pathogenesis. Gut Microbes 2013; 4: 505-31.

20. Lauritano EC, Gabrielli M, Scarpellini E, et al. Antibiotic therapy in small intestinal bacterial overgrowth: rifaximin versus metronidazole. Eur Rev Med Pharmacol Sci 2009; 13: 111-6.

21. Gatta L, Scarpignato C. Systematic review with meta-analysis: rifaximin is effective and safe for the treatment of small intestine bacterial overgrowth. Aliment Pharmacol Ther 2017; 45: 604-16.

22. Mégraud F, Bouffant F, Camou Juncas C. In vitro activity of rifaximin against Helicobacter pylori. Eur J Clin Microbiol Infect Dis 1994; 13: 184-6.

23. Sunny J Jr, Garcia CJ, McCallum RW. Interpreting the lactulose breath test for the diagnosis of small intestinal bacterial overgrowth. Am J Med Sci 2016; 351: 229-32.

24. Shah SC, Day LW, Somsouk M, Sewell JL. Meta-analysis: antibiotic therapy for small intestinal bacterial overgrowth. Aliment Pharmacol Ther 2013; 38: 925-34.

25. Di Stefano M, Miceli E, Missanelli A, et al. Absorbable vs. non-absorbable antibiotics in the treatment of small intestine bacterial overgrowth in patients with blind-loop syndrome. Aliment Pharmacol Ther 2005; 21: 985-92.

26. Pimentel M. Review of rifaximin as treatment for SIBO and IBS Expert Opin Investig Drugs 2009; 18: 349-58.

27. Holton J, Vaira D, Menegatti M, Barbara L. The susceptibility of Helicobacter pylori to the rifamycin, rifaximin. J Antimicrob Chemother 1995; 35: 545-9.

28. De Giorgio R, Stanghellini V, Barbara G, et al. Rifaximin and Helicobacter pylori eradication. Eur Rev Med Pharmacol Sci 1997; 1: $105-10$.

29. Quesada M, Sanfeliu I, Junquera F, et al. [Evaluation of Helicobacter pylori susceptibility to rifaximin]. Gastroenterol Hepatol 2004; 27: 393-6.

30. Gasbarrini A, Gasbarrini G, Pelosini I, Scarpignato C. Eradication of Helicobacter pylori: are rifaximin-based regimens effective? Digestion 2006; 73 Suppl 1: 129-35.

31. Nizhevich AA, Shcherbakov PL, Akhmadeeva ÉN, Khasanov RS. Rifaximin in combined treatment of the Helicobacter pylori infection in childhood. Eksp Klin Gastroenterol 2011; 1: 85-7.

32. Yun SP, Seon HG, Ok CS, et al. Rifaximin plus levofloxacin-based rescue regimen for the eradication of Helicobacter pylori. Gut Liver 2012; 6: 452-6.

33. Choi KH, Chung WC, Lee KM, et al. Efficacy of levofloxacin and rifaximin based quadruple therapy in Helicobacter pylori associated gastroduodenal disease: a double-blind, randomized controlled trial. J Korean Med Sci 2011; 26: 785-90.

34. Song M, Ang TL. Second and third line treatment options for Helicobacter pylori eradication. World J Gastroenterol 2014; 20: 1517-28.
Received: 4.10.2017

Accepted: 31.01 .2018 